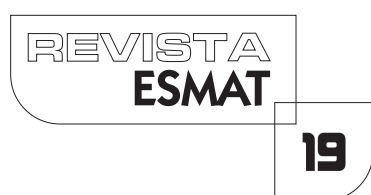

\title{
AS NOVAS DIRETRIZES CURRICULARES DE DIREITO E AS NOVAS DINÂMICAS DA PRÁTICA JURÍDICA NA UNIVERSIDADE FEDERAL DO PARÁ (UFPA)
}

THE NEW CURRICULAR GUIDELINES FOR LAW AND THE NEW DYNAMICS OF LEGAL PRACTICE AT UNIVERSIDADE FEDERAL DO PARÁ (UFPA)

Eliana Maria de Souza Franco Teixeira

Doutora em Direito (UFPA). Coordenadora de Ensino da Faculdade de Direito da Universidade Federal do Pará (UFPA). Professora da Pós-Graduação do Mestrado Profissional do NAEA/UFPA. E-mail: eliana.f.t@hotmail.com.

Luanna Tomaz de Souza

Doutora em Direito (Universidade de Coimbra). Diretora da Faculdade de Direito da Universidade Federal do Pará. Professora da Pós-Graduação em Direito da UFPA. E-mail: luannatomaz@ufpa.br.

Valena Jacob Chaves Mesquita

Doutora em Direito (UFPA). Diretora Acadêmica do Instituto de Ciências Jurídicas da Universidade Federal do Pará. Professora da Pós-Graduação em Direito da UFPA. E-mail: valenajacob@yahoo.com.br.

\section{RESUMO}

A preocupação com a qualidade da formação jurídica, consubstanciada por práticas de ensino/aprendizagem, condizentes com o que se espera de atuação qualitativa dos egressos universitários, atravessa a história dos cursos jurídicos e mantém-se até a atualidade. Assim, a pesquisa pretende responder ao seguinte questionamento: como a Faculdade de Direito da Universidade Federal do Pará (UFPA) tem atuado no âmbito da prática jurídica de modo a se adequar às Novas Diretrizes Curriculares? Os objetivos da pesquisa envolvem a descrição das Novas Diretrizes Curriculares n 05, de 20 I 8, e a demonstração do processo de gestão acadêmica na prática jurídica e os destaques de desenvolvimento da Faculdade de Direito desta Universidade. $\bigcirc$ método a ser utilizado será o dialético racional, que primará pela comparação e reflexão acerca das consequências e repercussões que serão provocadas, a partir da efetividade das alterações propostas. A primeira seção abordará as Novas Diretrizes Curriculares n 05 , de 20 I 8; a segunda abordará o Núcleo de Prática Jurídica; a terceira tratará das Clínicas de Direito; a quarta demonstrará o processo da gestão acadêmica para implantar as Novas Diretrizes Curriculares n 05, de 2018, como prática de consolidação do 
processo de ensino-aprendizagem, fomentando a pesquisa e a extensão. Destaca-se, ao final, o pioneirismo da Faculdade de Direito da Universidade Federal do Pará no processo de normatização dos estágios obrigatórios e não obrigatórios e da atuação das clínicas jurídicas.

PALAVRAS-CHAVE: Diretrizes Curriculares. Estágio. Prática Jurídica. Clínicas Jurídicas.

\begin{abstract}
The concern with the quality of legal training, embodied by teaching / learning practices, consistent with what is expected from the qualitative performance of university graduates, runs through the history of Legal Courses and remains until today. Thus, the research aims to answer the following question: how has the Faculty of Law at UFPA acted within the scope of legal practice in order to adapt to the New Curricular Guidelines? The research objectives involve the description of the New Curricular Guidelines $n^{\circ}$ 05/20 I 8 and the demonstration of the academic management process in legal practice and the development highlights of the UFPA Law School. The method to be used will be the rational dialectic, which will excel by comparison and reflection about the consequences and repercussions that will be provoked, based on the effectiveness of the proposed changes. The first section will address the New Curricular Guidelines $n^{\circ}$ 05/20 I 8; the second will address the Legal Practice Nucleus; the third will deal with Law Clinics; the fourth, will demonstrate the academic management process to implement the New Curriculum Guidelines 05/20 I 8, as a practice of consolidating the teaching / learning process, fostering research and extension. Finally, the pioneering work of the Faculty of Law of the Federal University of Pará in the process of standardizing mandatory and non-mandatory internships and the performance of legal clinics stands out.
\end{abstract}

KEYWORDS: Curricular Guidelines. Internship. Legal Practice. Legal Clinics.

\title{
I INTRODUÇÃO
}

A análise da Lei de I I de agosto de I827, que cria dois cursos jurídicos e sociais, um na cidade de São Paulo e outro na cidade de Olinda, demonstra a preocupação de formar brasileiros voltados aos estudos das leis brasileiras. Essa Lei organizou os cursos em nove cadeiras, com duração de cinco anos, determinando o que seria ministrado em cada um deles. A referida Lei também determinou a organização de docentes e funcionários.

O artigo 10 da mencionada Lei previu a regulamentação dos cursos jurídicos pelo Decreto, de 9 de janeiro de 1825, por meio de um Estatuto organizado pelo conselheiro de estado, Visconde da Cachoeira. Destaques do referido Decreto demonstram que os cursos jurídicos tinham de ensinar doutrinas e jurisprudência em geral, com o intuito de formar homens para serem magistrados, advogados, deputados e senadores, aptos a ocuparem o lugar de diplomata. 
Os conteúdos compreendiam direito natural, público, dos agentes, comercial, político e diplomático, além de prever a marcha e o método de ensino. No documento legal, ainda estava registrada a verificação de falta de bons estudos ao se referir ao ensino em Portugal, a partir da constatação de que muitos dos bacharéis formados lá não sabiam nada da rotina de seu trabalho, o que justificou a reforma ocorrida na Universidade de Coimbra, com estudos novos e planejamento mais adequado à formação de bacharéis nos cursos jurídicos.

Interessante observar que a idade mínima de ingresso era de dezesseis anos, além de ser necessária a aprovação em exame de línguas latina e francesa, retórica, filosofia racional e moral, e geometria. Embora aparentemente os conteúdos para entrada fossem menos abrangentes que os de hoje, a profundidade exigida era maior.

A institucionalização dos cursos jurídicos foi iniciada de forma controlada pelo Estado e continua sob o controle deste. Desde o início, houve preocupação com a formação sólida, prática e adequada dos bacharéis, a partir da observação dos formados em Portugal, sendo que essa inquietação é mantida pela busca da qualidade no processo de ensino e aprendizagem.

A preocupação com a qualidade dos bacharéis, consubstanciada por práticas de ensino-aprendizagem, condizentes com o que se espera de atuação qualitativa dos egressos universitários, atravessa a história dos cursos jurídicos e mantém-se até a atualidade. Assim, a pesquisa pretende responder ao seguinte questionamento: Como a Faculdade de Direito da Universidade Federal do Pará tem atuado no âmbito da prática jurídica de modo a se adequar às Novas Diretrizes Curriculares?

Os objetivos da pesquisa envolvem a descrição das Novas Diretrizes Curriculares $n^{\circ}$ 05, de 2018, e a demonstração do processo de gestão acadêmica na prática jurídica e os destaques de desenvolvimento da Faculdade de Direito da Universidade Federal do Pará.

método a ser utilizado será o dialético racional, que primará pela comparação e reflexão acerca das consequências e repercussões que serão provocadas, a partir da efetividade das alterações propostas.

Este artigo está estruturado da seguinte forma: a primeira seção abordará as Novas Diretrizes Curriculares nº5, de 2018; a segunda, o Núcleo de Prática Jurídica; a terceira tratará das Clínicas de Direito; a quarta demonstrará o processo da gestão acadêmica para implantar as Novas Diretrizes Curriculares n 05, de 2018, como prática de consolidação do processo de ensino-aprendizagem, fomentando a pesquisa e a extensão.

\section{O CONTEXTO DE DESENVOLVIMENTO DAS DIRETRIZES}

Compreender o processo de alterações das Diretrizes, de 2018, demonstrará o caminho percorrido com olhos voltados para o que se quer consolidar em termos de qualidade de ensino. Para isso, contudo, precisamos entender o contexto de seu desenvolvimento. 
As Diretrizes Curriculares nº9, de 2004, modificaram a Portaria $n^{\circ} 1$.886, de 30 de dezembro de 1994, determinando novas Diretrizes Curriculares para os cursos de Graduação em Direito. A Portaria $n^{\circ}$ 1.886, de 1994, estipulou as Diretrizes Curriculares para os cursos de Graduação em Direito, com 17 artigos, sendo observado que a carga horária mínima era de 3.300 horas de atividades, com duração de 5 anos e, no máximo, 8 anos letivos.

O documento não observava nem impunha que a organização das Instituições de Ensino Superior fosse específica e moldada, podendo intitular-se de Universidades, Centros Universitários, Faculdades Integradas ou Isoladas. $O$ artigo $2^{\circ}$ da referida Portaria determinou que os cursos jurídicos devessem desenvolver atividades de Ensino, Pesquisa e Extensão.

Entre as características dos cursos previstas pela Portaria n I.886, de 1994, estava a possibilidade de utilização de até $10 \%$ da carga horária do curso, a qual poderia ser realizada como atividades complementares. A matriz curricular compreendia dois eixos: o primeiro, previsto como Fundamental, remetia aos conteúdos de Introdução ao Direito, Filosofia Geral e Jurídica, Sociologia, Economia e Ciência Política; o segundo, denominado Profissionalizante, referia-se ao Direito Constitucional, Direito Civil, Direito Administrativo, Direito Tributário, Direito Penal, Direito Processual Civil, Direito Processual Penal, Direito do Trabalho, Direito Comercial e Direito Internacional. No quarto ano do curso de Graduação em Direito, era permitida a concentração em áreas de especialização.

Havia a necessidade de apresentação de monografia e realização de estágio com práticas reais e simuladas para a preparação de atividades de advocacia, magistratura, Ministério Público e demais profissões jurídicas. A preocupação com a área prática era evidente para formar bacharéis que conhecessem o mínimo da rotina profissional na área do Direito. Também se pode observar a interferência da Ordem dos Advogados no Brasil com relação ao estágio profissional de caráter extracurricular.

Não estava expresso que tipo de profissional se queria formar, mas, pela análise da Portaria $\mathrm{n}^{\circ} 1.884$, de 1994, pode-se compreender a intenção em permitir alguma flexibilidade, com a inclusão das especializações, e a partir do $4^{\circ}$ ano do curso era possível promover a especialização em áreas de interesse local, sempre considerando o mercado de trabalho.

Com uma década estabelecida das Diretrizes Curriculares, expressadas em 1994, ocorreu a modificação destas para o curso de Direito, passando a vigorar as Diretrizes Curriculares nº9, de 2004.

As relações sociais, políticas e econômicas fazem com que a sociedade seja dinâmica, e isso impulsiona a constante busca por mudança e atualização dos bacharéis em Direito. Embora exista uma contínua regulamentação, esta por si só não tem o condão de impor a formação de bacharéis mais qualificados, pois as pessoas envolvidas nesse processo precisam estar imbuídas pelas novas regras mínimas estabelecidas. 
A Resolução n 09, de 2004, contém treze artigos, menor que a anterior, mas muito mais pormenorizada e com pensamentos voltados ao desenvolvimento de um bacharel com formação tríade: geral, humanística e axiológica. A capacitação de análise, domínio de conceitos e de terminologias jurídicas, adequada argumentação com postura reflexiva, visão crítica e aptidão para aprendizagem autônoma e dinâmica tornam-se o cerne da nova regulamentação.

As diretrizes sob comento indicavam sete grupos de capacidades e competências que o curso de Graduação devia proporcionar, determinando a construção de um ciclo educacional: leitura, compreensão, elaboração de textos, atos e documentos jurídicos ou normativos; interpretação e aplicação do Direito; pesquisa e utilização da legislação, da jurisprudência, da doutrina e de outras fontes do Direito; adequada atuação técnicojurídica; correta utilização da terminologia jurídica; julgamento e tomada de decisões; e domínio de tecnologia e métodos para permanente compreensão do Direito.

A matriz curricular deveria compreender três eixos que envolviam os seguintes conteúdos: I. Fundamental: Antropologia, Ciência Política, Economia, Ética, Filosofia, História, Psicologia e Sociologia; 2. Profissional: Direito Constitucional, Direito Administrativo, Direito Tributário, Direito Penal, Direito Civil, Direito Empresarial, Direito do Trabalho, Direito Internacional e Direito Processual; e 3. Formaação Prática: Estágio Supervisionado, Trabalho de Conclusão de Curso e Atividades Complementares.

Observa-se, então, a inserção de novos conteúdos para a formação básica dos bacharéis, com destaque para Antropologia, Psicologia e História. O Brasil, diferente de outros Estados, mantém populações indígenas em áreas próprias, o que impõe a necessidade do conhecimento e diálogo entre os referidos campos do saber. Além disso, o Estado mantinha o compromisso de formar profissionais que compreendessem a dimensão da convivência com esses povos e outros que vivem no Estado Brasileiro, como os quilombolas e as populações tradicionais.

A História como matéria para se conhecer o passado, a fim de reconhecer o presente e transformar o futuro, é conteúdo que deve ser mantido na organização curricular do curso. A Psicologia como importante componente curricular para a compreensão das relações humanas e percepção dos embates jurídicos que circundam a vida em sociedade.

O Eixo Fundamental foi ampliado no intuito de demonstrar ao profissional que era formado que o saber promovido pelo Ensino do Direito não era suficiente para responder às questões concretas sociais, o que só se tornava possível quando os professores compreendessem que deviam se comprometer com a realidade inter e transdisciplinar.

As diretrizes em questão reforçavam a necessidade de planejamento dos docentes, com a entrega dos Planos de Ensino aos discentes, que deveriam contemplar no mínimo: os conteúdos; as atividades; a metodologia do processo de ensinoaprendizagem; e os critérios, procedimentos e mecanismos de avaliação. O sucesso de 
qualquer regulamentação e de curso estava e está nas mãos dos docentes, porque eles representam a força motriz dessa engrenagem, devendo agir de forma criteriosa e planejada, estimulando e tornando o ciclo de ensino-aprendizagem atraente e desejável pelos seus discentes.

É possível constatar que a exigência de formação humanística dos discentes fez com que as matrizes curriculares contemplassem o ensino de conteúdos voltados aos Direitos Humanos, o que por si só não ensejava o alcance do objetivo esperado: a compreensão de que o ensino do Direito tem como objetivo o ser humano, e não a técnica jurídica, reforçando o primeiro objetivo em preparar bacharéis com formação, geral, humanística e axiológica, sempre considerando a justiça social.

Segundo locohama (201 I, p. 57), a perspectiva pluralista com ampliação da concepção do Direito demonstra o trânsito entre o Direito Estatal e o Comunitário para o Direito justo. Além de tal aspecto, o autor abordou três concepções do Direito, sendo que importa esclarecer a concepção humanista trazida pela Resolução n 09, de 2004 , que para locohama (201 I , p. 58-59) significa que as interpretações do Direito devem manter seu vínculo imprescindível para servir ao ser humano, assegurando-se que o Direito não será manobrado pelo Estado e desconsiderando o interesse, a participação e os direitos das pessoas.

Além dos estudos de graduação, as diretrizes contemplaram a ideia de estudos continuados, como aperfeiçoamento e atualização dos egressos das Instituições de Ensino Superior, a partir da possibilidade de integração entre graduação e pósgraduação.

\section{AS NOVAS DIRETRIZES CURRICULARES E A PRÁTICA JURÍDICA}

As Novas Diretrizes Curriculares constantes da Resolução n 05, de 2018, estabelecem mudanças importantes no que se refere à relação entre o ensino, a pesquisa e a extensão, bem como à nova roupagem da prática jurídica e ao fortalecimento das mobilidades nacionais e internacionais.

A relação entre o ensino, a pesquisa e a extensão é enfatizada pela determinação de que tem de ser demonstrada de forma discriminada a forma de como ocorrerá a conexão entre o tripé acadêmico. Quer dizer, na prática, a pesquisa produzirá resultados que repercutirão na sala de aula e serão direcionados à comunidade externa por meio de oficina e palestras.

A ideia da manutenção do ensino como parte sectária vai ter de ser abandonada e o conteudismo também. Para que o planejamento seja executável haverá um ou alguns problemas a serem solucionados no percurso das disciplinas que se alimentarão dos resultados das pesquisas realizadas. Essa nova tônica na relação do tripé universitário demandará uma mudança de postura dos docentes, sobretudo dos que atuam na pósgraduação que nem sempre desenvolvem pesquisas associadas ao ensino na graduação.

As Novas Diretrizes concederam importância também à extensão, a partir da menção expressiva de clínicas e projetos como atividades de extensão, sendo ainda mais 
ampliada com a Resolução CNE/CES n 07, de 20 I 8, que a extensão tomou corpo de obrigatoriedade percentual nos Projetos Pedagógicos para os cursos de Direito.

Destacam-se algumas mudanças: de nomenclatura como foi o caso de eixos para perspectivas formativas; observância de Planos de Ensino vinculados ao desenvolvimento do perfil do egresso, podendo prever atividades extraclasse com participação do docente; alteração de nomenclatura, aliada à inclusão de mais competências cognitivas (antes denominadas competências e habilidades); utilização de metodologia jurídica para aplicar conceitos, estruturas e racionalidades fundamentais ao exercício do Direito; desenvolver a cultura do diálogo e o uso de meios consensuais de solução de conflitos; desenvolver a cultura do diálogo e o uso de meios consensuais de solução de conflitos; aceitar a diversidade e o pluralismo cultural; desenvolvimento perspectivas transversais sobre direitos humanos.

Algumas novidades trazidas pelas Novas Diretrizes dizem respeito à aproximação com o mercado de trabalho quando estabelece que o projeto pedagógico do curso deva apresentar planejamento estratégico, missão, visão e valores do curso.

No âmbito das perspectivas formativas, antes eixos, o conteúdo de Teoria do Direito passa a compor a formação técnico-jurídica, e a prática jurídica, inserida na formação prático-profissional (antes eixo de formação prática), é ampliada, pluralizandose as possibilidades de práticas para além do estágio curricular supervisionado, podendo envolver todas as atividades práticas reais e simuladas, com concentração no desenvolvimento de práticas de resolução consensual (mediação, conciliação e arbitragem) de conflito e práticas de tutela coletiva, bem como a prática de processo judicial eletrônico.

A carga horária do curso será de 3.700 horas, com até 20\% de carga horária destinada às atividades complementares e à prática jurídica.

As atividades complementares antes estavam ligadas às atividades realizadas fora da sala de aula, sendo voltadas para relações com o mercado de trabalho e com ações de extensão; todavia, pelas atuais diretrizes, as atividades complementares compreendem competências obtidas dentro e fora do ambiente acadêmico, mas podendo ser articulada com a oferta de componentes curriculares que componham a estrutura curricular.

Manteve-se a obrigatoriedade da realização de Trabalho de Curso, antes de nominado Trabalho de Conclusão de Curso. As Novas Diretrizes Curriculares também enfatizaram a interdisciplinaridade e transdisciplinaridade na construção de conhecimentos e para resolução de problemas sociais emergentes.

Percebe-se assim um foco na diversidade da prática jurídica, na relação com o mercado de trabalho e com os problemas contemporâneos. Esse horizonte tem sido apontado há certo tempo, em especial quanto ao estágio obrigatório.

A partir da edição da Resolução CNE/CES n 9, de 2004, que instituiu as Diretrizes Curriculares Nacionais (DCN) para os cursos de Direito, o estágio supervisionado, componente curricular obrigatório, deveria ser realizado somente no interior da própria instituição, por meio do Núcleo de Prática Jurídica (NPJ). 
Em 17 de julho de 20 17, a Câmara de Educação Superior do Conselho Nacional de Educação emitiu a Resolução CES/CNE n³, de 20 I7, permitindo que as atividades do estágio supervisionado obrigatório dos cursos de Direito pudessem ser realizadas em outros ambientes além do Núcleo de Prática Jurídica da instituição de ensino superior.

\section{O ESTÁGIO OBRIGATÓRIO E A PRÁTICA JURÍDICA NA UNIVERSIDADE FEDERAL DO PARÁ(UFP)}

O pioneirismo da Faculdade de Direito da Universidade Federal do Pará fica evidente nesse processo. Em 5 de junho de 20 17, a Resolução FAD no 06, de 20 17, da Faculdade de Direito, normatizou os estágios obrigatórios e não obrigatórios. Nessa Resolução, anterior à Resolução CES/CNE n 3, de 2017, a Faculdade de Direito autorizou que o estágio obrigatório fosse cumprido para além do Núcleo de Práticas Jurídicas (NPJ), nos seguintes termos:

Art. $5^{\circ}$. $\bigcirc$ estágio interno pode ser desenvolvido dentro das seguintes modalidades de operacionalização para atender os componentes do eixo de formação prática do percurso curricular da faculdade de direito:

I- Escritório de Prática Jurídica (EPJ): realizado dentro do Núcleo de Prática Jurídica, com atribuições de atendimento aos assistidos e prática profissional real.

II- Clínica Jurídica: realizado em uma das Clínicas do Instituto de Ciências Jurídicas, através da realização de prática jurídica temática pelo atendimento a casos pontuais, estudos de casos e/ou assistência judiciária ou extrajudicial, inclusive nos sistemas internacionais de direitos humanos.

III- Centro Judiciário de Solução de Conflitos e Cidadania (CEJUSC): em decorrência de cooperação técnica firmada com o Tribunal de Justiça do Estado do Pará para a realização de sessões de conciliação e mediação que possibilitem a pacificação dos conflitos dos assistidos e habilitem os discentes a utilizarem os meios alternativos de solução de conflitos e a adotarem uma cultura de paz;

IV- Ações de Desempenho Profissional (ADP): cuja finalidade é oferecer atividades diversas relacionadas à prática jurídica, através de ações externas para elaboração de peças, pareceres, estudos de caso ou atividades diversas de prática jurídica coordenada pelo NPJ.

No estágio obrigatório externo à Universidade Federal do Pará, o(a) discente fica matriculado(a) na disciplina Prática Forense, mas apresenta um relatório mensal das atividades desenvolvidas no referido órgão, o que será avaliado por um professor do curso. Foram feitos convênios com variadas instituições para estimular essa diversidade 
para a prática jurídica, como o Tribunal de Justiça, a Defensoria Pública, diferentes escritórios, dentre outras.

O Núcleo de Prática Jurídica da Universidade Federal do Pará é um dos mais antigos serviços que esta presta à comunidade, e funciona desde a década de 60, quando a Faculdade de Direito ainda estava localizada no Casarão do Largo da Trindade, sendo chamado anteriormente de Escritório de Prática Jurídica (UFPA, 20 I I).

Este foi considerado a principal prática extensionista da Faculdade de Direito, mesmo surgindo, principalmente a partir dos anos 2000, outras experiências como os núcleos de assessoria popular, em especial o Núcleo de Assessoria Jurídica Universitária Popular Aldeia Kayapó e o Núcleo Isa Cunha (GOMES, 20 I 8).

Na década de 60, por meio da Lei n 4.215, de 1963, estabeleceu-se a necessidade de estágio como regra para o ingresso nos quadros da Ordem dos Advogados do Brasil (OAB), o que trouxe grande relevância para sua prática. A Resolução n³, de 1972, do Conselho Federal de Educação (CFE), introduziu a disciplina Prática Forense no currículo, sob a forma de estágio supervisionado. A Portaria $n^{\circ}$ 1.886, de 1994, do Ministério da Educação e Cultura (MEC), elegeu o estágio como elemento central da atuação do Núcleo de Práticas Jurídicas, exigindo, por exemplo, a destinação de instalações apropriadas (PEREIRA e OLIVEIRA, 2017).

Foram surgindo, contudo, ao longo do tempo, muitas críticas ao modelo dos Núcleos de Prática Jurídica. Segundo Bello e Ferreira (20l8), os processos judiciais geralmente envolvem casos repetitivos, contencioso de massa, com complexidade jurídica baixa, envolvendo questões patrimoniais. $O(A)$ discente acaba recebendo passivamente instruções sobre as soluções, elaborando peças processuais a partir de modelos e acompanhando parcialmente a tramitação dos processos.

Para dinamizar a atuação do Núcleo de Práticas Jurídicas, considerando a importância da prática jurídica, foi feito convênio com a Defensoria Pública do Estado (DPE, 20I5), que passou a encaminhar casos e atender à fase judicial destes, e mais recentemente, com o Centro Judiciário de Solução de Conflitos (CEJUSC)'.

Mesmo com as mudanças, ainda é necessário diversificar a prática jurídica. Por isso, o(a) aluno(a) pode fazer o estágio externo em escritórios e órgãos públicos. Ademais, uma das modalidades possíveis de atividade prática é por meio das Clínicas Jurídicas.

\section{AS CLÍNICAS JURÍDICAS NA UNIVERSIDADE FEDERAL DO PARÁ}

As clínicas jurídicas surgiram tanto na América do Norte quanto na América Latina, com o primordial objetivo de mudar a metodologia tradicional do ensino jurídico.

UFPA. Centro Judiciário de Solução de Conflitos da UFPA será inaugurado em agosto. Disponível em: https://www.portal.ufpa.br/index.php/ultimas-noticias2/I0437-centrojudiciario-de-solucao-de-conflitos-da-ufpa-sera-inaugurado-em-agosto. Acesso em: II nov. 2019. 
Juntamente com a criação de diversas clínicas jurídicas, foram criadas clínicas específicas para tratar do tema dos direitos humanos, ou seja, as clínicas de direitos humanos, que, por sua vez, têm conseguido ter um impacto social em todo o continente.

Não existe um conceito único, modelo ou formato de clínica de direitos humanos, como sustenta Hurwitz (20 I I , p. I 0 I): "Eu acho que a maioria concorda que não existe um paradigma único para as clínicas de direitos humanos. Elas são diversas e, como a advocacia em direitos humanos em si, inovadora e contextualizada". Em geral, a clínica de direitos humanos nos Estados Unidos da América é um curso prático que tem como referência o direito internacional e que engaja os estudantes em técnicas de advocacia em direitos humanos (HURWITZ, 2006, p. 38).

Vale destacar que esse tipo de clínica geralmente não é centrado no atendimento individual de pessoas (client-centred), como outras clínicas fazem (exemplo: clínicas de refugiados ou imigrantes). As estratégias, segundo a professora estadunidense, às vezes são jurídicas (litígio, assistência jurídica, advocacia legislativa), mas, na maioria das vezes, são "não jurídicas" (educação em comunidades, investigação e elaboração de relatórios). Às vezes, são realizadas em tribunais, mas, o que é mais comum, na imprensa, nas ruas, em espaços governamentais e em conferências mundiais (HURWITZ, 2006).

No Brasil, a advocacia em direitos humanos envolve estratégias, como o litígio, o monitoramento, a elaboração de relatórios, o desenho de políticas e legislações, a organização e o advocacy, mecanismo de pressão utilizado pelos movimentos para alcançar suas demandas. As clínicas de direitos humanos possibilitam "introduzir esta variedade de práticas aos estudantes de Direito, e engajá-los criticamente e na prática no desenvolvimento de uma ou mais dessas habilidades" (HURWITZ, 2006, p. 39). Podese dizer assim que o método clínico busca a intervenção estratégica em casos de grande impacto os quais envolvem grupos sociais, utilizando variadas formas de intervenção (BELLO e FERREIRA, 20।8).

As clínicas de direitos humanos na América do Norte e América Latina, em sua maioria, trabalham com atividades de extensão, ou seja, os estudantes têm de se relacionar com entidades parceiras para desenvolver seus projetos. Já as atividades de Programas de Direitos Humanos, por exemplo, estão mais focadas em pesquisas e atividades de ensino, como seminários e debates institucionais.

Hurwitz (2006) observa que algumas faculdades de Direito nos Estados Unidos têm ambos: programas e clínicas de direitos humanos. Afirma, ainda, que a primeira clínica de direitos humanos surgiu em 1989 e que lá existem, atualmente, pelo menos 15 Faculdades de Direito das 185 credenciadas. Para os estudantes de Direito, participar de clínicas de direitos humanos durante a graduação pode trazer inúmeros benefícios. Primeiro, eles aprendem que o Direito pode ser um meio para mudanças sociais, e não um fim em si mesmo. E, adicionalmente, adquirem habilidades de advocacia em geral que podem também ser utilizadas para a advocacia em direitos humanos, ou seja, é importante destacar que essas habilidades são úteis não apenas para a advocacia em direitos humanos, mas também para qualquer profissão jurídica. Essas habilidades, 
segundo Hurwitz (2006, p. 30), dão ênfase:

[...] na escrita de peças jurídicas; na boa comunicação oral; na habilidade de pensar criticamente e de desenvolver estratégias efetivas para solucionar problemas; na capacidade de ser organizado mesmo sob pressão e com demandas concorrentes; no trabalho em grupo; em desenvolver uma forte habilidade de pesquisa, incluindo pesquisa de fatos e pesquisa em direito interno e internacional; e a habilidade de reconhecer e resolver situações de papéis e responsabilidades profissionais.

Clínicas de Direitos Humanos surgiram na América do Norte, na década de 1990, e as clínicas de interesse público, na América Latina a partir da mesma década. Segundo Lapa (20|4), no Brasil, percebe-se um primeiro movimento de criação de clínicas jurídicas a partir do século $X X \mathrm{I}$, e esse movimento tem sido impulsionado pelo protagonismo das clínicas de direitos humanos:

Diante da crise do ensino de Direito no Brasil, os cursos jurídicos ainda hoje buscam um espaço para articular a teoria com a prática jurídica e, ainda, formar profissionais da área do Direito comprometidos com a Justiça Social. Assim, além dos outros espaços universitários existentes, nesta última década, diferentes formatos de clínicas jurídicas surgiram no Brasil. É possível identificar diversos espaços dentro dos cursos jurídicos brasileiros que desenvolvem atividades de ensino, pesquisa e/ ou extensão na temática dos direitos humanos, em especial, centros, núcleos, laboratórios ou institutos de direitos humanos. No entanto, esses espaços denominados clínicas jurídicas somente surgiram a partir do século XXI. (LAPA, 20 I4, p. 72)

A Faculdade de Direito da Universidade Federal do Pará possui duas Clínicas Jurídicas de Direitos Humanos: a de Direitos Humanos da Amazônia (CDHA) e a de Atenção à Violência (CAV).

Ambas as Clínicas integram a Rede Amazônica de Clínicas de Direitos Humanos. Em 20 I I, na Universidade Federal do Pará (UFPA), ocorreu a criação da Rede Amazônica de Clínicas de Direitos Humanos com apenas três outras instituições de ensino superior. Posteriormente foram agregadas mais cinco instituições, contabilizando oito, quais sejam: "Universidade Federal do Pará (UFPA), Universidade Federal do Oeste do Pará (UFOPA), Universidade de Brasília (UnB)|2, Universidade Federal do Mato Grosso (UFMT), Universidade Federal de Roraima (UFRR), Universidade Federal do Sul e Sudeste do Pará (UNIFESSPA), Universidade Federal do Amazonas (UEA) e Universidade da Região de Joinville (UNIVILLE) (RIBEIRO, 20 I 6). 
A Clínica de Direitos Humanos da Amazônia foi criada, em 201 I , como pertencente ao Laboratório de Direitos Humanos do Programa de Pós-Graduação em Direitos Humanos (PPGD) da Universidade Federal do Pará; no entanto, sua instalação ocorreu, em 2012, como pertencente ao Laboratório em Direitos Humanos do Programa de Pós-Graduação em Direito da Universidade Federal do Pará (PPGD/UFPA).

Embora a Clínica de Direitos Humanos da Amazônia (CIDHA) decorra dos modelos norte-americanos e de alguns países latino-americanos, destaca-se por congregar a capacitação profissional dos estudantes de Graduação e de Pós-Graduação em Direito, dos cursos de Mestrado e de Doutorado, o que a diferencia das demais Clínicas Jurídicas de Direitos Humanos do País. No entanto, resta claro para esta Clínica que sua principal finalidade não é a de habilitar os discentes para a prática jurídica regular, como se apresenta significativa parte dos modelos latino-americanos, mas fazer com que o estudante ultrapasse o espaço das Universidades e da academia tradicional e se aproprie da realidade social. Nesse sentido, ela realiza atividades voltadas para o assessoramento ou representação legal, incentivando os discentes a desenvolverem outras habilidades ante um caso concreto e real, como: oitiva, argumentação, análise de problema, definição de estratégias, identificação da repercussão social e legal da demanda, elaboração de relatórios e pareceres, uso de campanhas e rede sociais.

A Clínica de Direitos Humanos da Amazônia busca ainda avaliar o conhecimento teórico dos discentes adquirido em outras disciplinas curriculares, quando demandados a aplicarem tal conhecimento em casos concretos, bem como identificar omissões ou distorções legislativas, prática abusivas ou ilegais por parte da Administração Pública ou do Poder Judiciário, discutindo administrativa e judicialmente os instrumentos de garantia de direitos, principalmente diante dos direitos fundamentais. Tal prática permite identificar novas áreas de pesquisa, para busca de soluções jurídicas.

Nesse sentido, a Clínica de Direitos Humanos da Amazônia desenvolve suas atividades partindo de diferentes metodologias, definindo critérios para seleção de casos, com repercussão social e jurídica, sejam individuais ou coletivos, que fortaleçam ou questionem precedentes jurisprudenciais, que apontem para questões lacunosas ou contraditórias do ordenamento jurídico, com atuação em demandas judiciais ou em outras instâncias etc. Em sendo sua atividade voltada para casos concretos e reais, esta Clínica valoriza o aspecto pedagógico que o caso proporciona para o desenvolvimento da habilidade do estudante de Direito, assim como incentiva que suas "ações de interesse público" ensejem transformações na sociedade, principalmente no tocante à garantia dos direitos humanos.

No que diz respeito à estrutura organizacional da mencionada Clínica, ela é composta por docentes coordenadores de projetos, todos vinculados ao Programa de Pós-Graduação em Direito, bem como de discentes dos cursos de Mestrado, Doutorado e da Graduação em Direito. O grupo de discentes da graduação do curso de Direito é composto por estagiários, com recebimento de bolsas de estudos e voluntários, com carga horária de trabalho reduzida e sem o recebimento de benefício 
econômico. No grupo de discentes voluntários, identificou-se a presença de exbolsistas da Clínica, que permanecem desempenhando atividades com as quais tenham externado afinidade, trabalhando em cooperação com os recém-bolsistas da Clínica de Direitos Humanos da Amazônia.

A Clínica de Atenção à Violência (CAV) foi criada, em 2016 , vinculada à Faculdade de Direito. É um espaço voltado para a formação acadêmica dos(as) alunos(as) da Faculdade de Direito e, para além disso, ao atendimento e serviço à comunidade, a partir da humanização do atendimento jurídico e de mecanismos de litigância estratégica. A Clínica de Atenção à Violência oferece às pessoas em situação de violência um atendimento que vai além da judicialização das demandas,

Ela busca promover direitos fundamentais a pessoas hipossuficientes que se encontram em situação de violência oferecendo atendimento jurídico gratuito ao lado dos(as) alunos(as) da Faculdade de Direito que optam por cursar a matéria de Prática Forense na Clínica.

Nesse cenário, os(as) estudantes assumem um papel importante ao se tornarem responsáveis pelos casos propostos e, assim, passam a desenvolver habilidades interdisciplinares, desde o atendimento ao público, quando devem trabalhar o tratamento às pessoas em situação de violência e procurar reconhecê-las enquanto sujeitos de direito, até à resolução do caso, quando devem considerar as particularidades de cada situação, a fim de buscar ações estratégicas e plurais para o enfrentamento das situações propostas.

A equipe é formada por profissionais e estudantes do Direito, do Serviço Social, da Enfermagem, da Psicologia. Desde o seu primeiro atendimento, em outubro de 2016 , a Clínica de Atenção à Violência registrou 107 casos de pessoas em situação de violência. Atualmente, há apenas 17 casos ainda em andamento. A partir dos casos, os(as) discentes refletem em conjunto sobre as possíveis formas de resolução e discutem propostas de incidência mais ampla sobre as temáticas envolvidas, em forma de litigância estratégica. Diversas atividades foram realizadas, como a elaboração de cartilhas, projetos de lei, protocolos, petições ao sistema interamericano, dentre outros.

Em 6 de março de 2018, a Resolução FAD/IC] n 02, de 2018, passou a regulamentar a atuação das clínicas. Nos termos da referida Resolução:

Art. $3^{\circ}$. Considera-se como metodologia clínica, estratégicas que conduzam à interação entre ensino, pesquisa e extensão baseadas em atuação em casos paradigmáticos junto a Judiciário, órgão reguladores, setores governamentais ou organismos internacionais, utilizando advocacy e/ou litigância estratégica.

Os(as) docentes vinculados(as) às clínicas podem assim ministrar a disciplina Prática Forense, mas na modalidade clínica. A primeira disciplina de prática clínica foi ministrada, em 20 I 8, pela Clínica de Atenção à Violência, com foco na defesa das mulheres. 
As disciplinas podem conter de três a dez discentes e durarão um período letivo. Ao final de cada período letivo, a disciplina deverá ter como resultado a formulação e sistematização de propostas para a solução de problemas jurídico-sociais, mediante a formulação de programas, contratos, projetos de política pública, propostas de legislação, material didático, petições ou quaisquer outras medidas ou ações jurídicas.

\section{CONSIDERAÇÕES FINAIS}

A partir da evolução das diretrizes curriculares do curso de Direito pôde-se observar que houve um gradativo foco na diversidade da prática jurídica, na relação com o mercado de trabalho e com os problemas contemporâneos.

No âmbito do estágio obrigatório, esse horizonte começou a ser apontado por meio da Resolução CES/CNE n³, de 2017, e se consolidou com a Resolução n 05, de 2018.

pioneirismo da Faculdade de Direito da Universidade Federal do Pará fica evidente nesse processo com a edição da Resolução FAD n 06, de 20 I7, da Faculdade de Direito, que normatizou os estágios obrigatórios e não obrigatórios, e por meio da Resolução FAD/IC n n 02, de 20 I 8, que regulamentou a atuação das clínicas jurídicas.

Pugnou-se, por meio desses instrumentos, pela diversificação do estágio obrigatório e pelo fomento de uma prática jurídica mais pautada no mercado de trabalho, e também na justiça social.

\section{REFERÊNCIAS}

BELLO, Enzo; FERREIRA, Lucas Pontes. Clínicas de direitos humanos no Brasil: um estudo sobre seu processo de implementação e funcionamento na prática e no ensino jurídico. Revista de Estudos Constitucionais, Hermenêutica e Teoria do Direito (RECHTD) I0(2): I 70- | 82, maio-agosto 2018.

BRASIL. Lei de I I de agosto de I827. Disponível em: http://www.planalto.gov.br/ccivil_03/leis/lim/LIM- I I-08- | 827.htm. Acesso em: 7 set. 2019.

BRASIL. Portaria ${ }^{\circ} 1.886 / 94$. Disponívele m: https://www.migalhas.com.br/arquivo_artigo/art20 I00 108-03.pdf. Acesso em: 7 set. 2019.

BRASIL. Resolução CNE/CES n 09, de 29 de setembro de 2004. Disponível em: http://portal.mec.gov.br/cne/arquivos/pdf/rces09_04.pdf. Acesso em: 22 set. 2019. 
BRASIL. Resolução CNE/CSE n 03, de 17 de julho de 2017. Disponível em: http://portal.mec.gov.br/docman/julho-2017-pdf/6808|-rces003-17-pdf/file. Acesso em: 22 set. 2019.

BRASIL. Resolução CNE/CSE n 05, de 17 de dezembro de 2018. Disponível em: http://portal.mec.gov.br/index.php?option =com docman\&view $=$ download\&alias $=1$

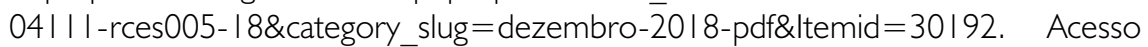
em: 7 set. 2019.

DPE. UFPA é nova parceira da Defensoria Pública. 21/10/2015. Disponível em: http://www2.defensoria.pa.gov.br/portal/noticia.aspx?NOT_ID $=1870$. Acesso em: II nov. 2019.

FRANCO, Patrícia Lopes Jorge; LONGAREZI, Andréa Maturano. O Desenvolvimento decente em um processo didático formativo. Disponível em: file://Users/eliana/Downloads/-arquivos-86e8f7ab32cfd I 2577bc26 I 9bc63569018.pdf. Acesso em: 9 set. 2019.

GOMES, Raphael Carmesin. A ExtensãoUniversitária Como Práxis Educativa Do Bacharel em Direito da Universidade Federal Do Pará: O caso do Núcleo de Assessoria JurídicaUniversitária Popular Aldeia Kayapó (2004-2014). Dissertação. Mestrado em Educação da UFPA. 2018.

HURWITZ, Deena R. Engaging Law students through human rights clinics: a perspective from the United States. Australian Journal of Human Rights - AJHR. Sidney, I I .2 (2), p. 37-5। , 2006.

HURWITZ, Deena R. Teaching to the Paradoxes: Human Rights Practice in U.S. Law School Clinics. Maryland Journal of International Law, vol. 26, p. I0 I I 29, 201 I .

IOCOHAMA, Carlos Hiroshi. O ensino do Direito e a separação dos Eixos Teórico e Prático: interrelações entre a aprendizagem e ação docente. Universidade de São Paulo. 201।. 320 p. Disponível em: http://Users/eliana/Downloads/CELSO_ HIROSHI_IOCOHAMA\%20(I).pdf. Acesso em: 7 set. 2019.

LAPA, Fernanda Brandão. Clínicas de Direitos Humanos: uma proposta pedagógica para a educação jurídica no Brasil. Rio de Janeiro: Lumen Juris, 2014.

LAPA, Fernanda Brandão; MESQUITA, Valena Jacob Chaves. Clínica de Direitos Humanos: formando defensores de Direitos Humanos no Brasil. Aracê - Direitos Humanos em Revista, v. 2, n. 2 (20/5). Disponível em:file://arace.emnuvens .com.br/arace/article/view/23/2। 
LONGAREZI, Andréa Maturano; MOURA, Manoel Oriosvado de. A intervenção didático-formativa como procedimento de pesquisa com ensino desenvolvimento. Disponível em: http://webcache.googleusercontent.com/search?q=cache :http://www3. fe.usp.br/secoes/inst/novo/agenda_eventos/inscricoes/PDF_SWF/ 63397.doc\&gws_rd=cr\&dcr=0\&ei=uEbfWYSkGMS̄5wATqqLigCg. Acesso em: 7 set. 2019.

MORAES, Patrícia Regina et al. O ensino jurídico no BRASIL. Disponível em:http://unifia.edu.br/revista_eletronica/revistas/direito_foco/artigos/ano20 I4/ensin o juridico.pdf. Acesso em: 7 set. 2019.

NIT-RIO. INOVAÇÃO. Conceitos básicos relacionados às atividades de pesquisa científica e tecnológica. Disponível em: http://www.nitrio.org.br/downloads/inovacao .pdf. Acesso em: 7 set. 2019.

OLIVEIRA, Rezilda Rodrigues; PEREIRA, Francinete Paula Alves. Avaliação apreciativa de um Núcleo de Práticajurídica. Revista Direito GvSão Paulo. V. 13 N.2. P. 537-566. maio-ago. 2017.

RIBEIRO, C.F.T. 2016. Rede Amazônica de Clínicas de Direitos Humanos. In: N.M. SILVA NETO et al. (orgs.), Educação clínica em direitos humanos: experiências da Rede amazônica de clínicas de direitos humanos. Rio de Janeiro, Lumen Juris, p. 9-20.

UFPA. UFPA presta atendimento jurídico à comunidade. 30.12.2011. Disponível em:https://ww2.ufpa.br/imprensa/noticia.php?cod=54 I 5. Acesso: I I nov. 2019.

Recebido em: 17/02/2020

Aprovado em: 26/04/2020 